\title{
"On the Economic Concept of Mental Health: A Probing Inquiry", an Author's Review
}

\author{
Pablo Levín*
}

Faculty of Economics, University of Buenos Aires (FCE/UBA), Argentino

\section{Article Info}

\section{Article Notes}

Received: May 16, 2018

Accepted: July 26, 2018

\section{*Correspondence:}

Dr. Pablo Levín, Faculty of Economics, University of Buenos Aires (FCE/UBA), Argentina; E-mail: penlevin@gmail.com.

C 2018 Levin P. This article is distributed under the terms of the Creative Commons Attribution 4.0 International License.

\section{Keywords}

Aspiration

Contemporaneity

Ethology

Heteronomy

Human culture

Ideology

Political eonomy

Psychiatry

\section{Abstract}

Both this mini-review and the reviewed article were composed by this author (an economist), to probe into the ample but as yet hardly explored interface between two disciplines (Psychiatry and Political Economy) that have mostly grown heretofore with their backs turned to each other. In facing such a very large and complex almost newfound interdisciplinary field -itself a decisive step towards the integration of an all-encompassing philosophy of culture; a full systematic discussion is neither to be announced nor expected. At some point however our statements may appear apodictic in form and emphatic in tone; but please bear in mind that these excesses are just meant to make our point. Our purpose is to call for further discussion, with a serious caveat as to the danger entailed in interdisciplinary conversation, of begetting still another syncretic contraption.

We hopefully feel instead, that this abridged version comes closer than the earlier article; to the desideratum of a synthetic concept; potentially impinging upon: i.e., constituting; the vast area where these two disciplines overlap; by developing the concept of a "triple culture aporia (TCA)" -as a theoretical archetype for Ideology.

The TCA concept has to saddle over upon the interdisciplinary boundaries we're here concerned with; shedding new light on the absolute originality of today's human condition. To make this clearer, we should bring forth the concept of historical heteronomy, to wit, contemporary human's self-inflicted incapacity for becoming our own full- fledged contemporaries. In a nutshell: chronologic contemporariness is given to us as a matter of fact; but prevailing institutionalized education falls short from -or indeed systematically precludes; preparing us to raise ourselves up to present historical contemporaneity; to confront its exigencies, to reap its high rewards; the latter being the utmost specifically human aspiration!

It is our deep conviction, that a (the?) main source of our individual distresses and sufferings -included those that bring us as patients to the psychiatrist's office; are to be sought among our failures in our quest for Bildung; not constrained into its xviii enlightenment still incipient notion; but open to its urgently needed updated concept...which is what this review is about.

Our article reviewed herein ${ }^{4}$, dealt with the prospects of an alliance between Psychiatry and Political Economy, and found them promising. Wide new horizons of knowledge and practical accomplishment were envisioned; to be eventually opened by such cooperation. In the time elapsed since its publication such expectations were somewhat sobered but not at all weakened. Opening a dialogue with interlocutors of such a different formation is itself quite a task. But even this is almost negligible contrasted 
with the breath, complexities and dramatic urgency the ensuing proposal entails. In this respect, the thesis we upheld in the article we're revising was that what our chronological contemporaries (ourselves included) need most, is to acquire contemporariness as historical beings: or, to become our own historical contemporaries.

We know how difficult this is for an individual to elaborate this exigency: i.e. become willing and able to acknowledge and elaborate our potential as individuals living present history; as a workable aspiration, and grow up to it. And we feel it's safe to say that the circumstances thwarting us from seeking -and eventually meeting; it, is a main source of both individual and collective dissatisfaction, frustration, and suffering. In writing the article it seemed to us a reasonable guess that this problem haunts the psychiatrist's patient and obfuscates his tribulations; and we felt sure that economists (some, if not most) may be of some help in this respect.

Indeed, when we wrote the article we were already conceiving the scope of political economy as reaching beyond the narrow boundaries conventionally ascribed to our profession ${ }^{3}$. Having written the article we're reviewing -on a question that had been hovering for some time above our daily theoretical concerns mainly focused in economic theory; together with scant but stimulating feed-back brought about by that publication; worked upon our group at the Research Centre on Development Planning, at the Buenos Aires University (CEPLAD/FCE/ UBA) as an intellectual alarm-clock of sorts; that drew our main attention not directly to psychiatry, but to a "third" common field; which we deem not as if it was still one more specialized niche; but as potentially the sole universal ground whereupon all sciences are hopefully bound to meet the sooner the better; in a grand synthetic differentiated unit. The standard name for it is of course Philosophy, which after being crowned as the queen of all sciences some two hundred years ago, seems sorely typecast today as a particular item among others, enlisted in the standard curricula. To circumvent fatal misunderstanding; we use the word Philosophy with a further specification (or make sure our interlocutor has come to terms with it, so it goes implicit); and, instead of referring to philosophy at large, we pointedly denote the "philosophy of culture", and more pointedly "philosophy of Aspiration"2.

Against such a background it becomes clear enough that working towards the integration of sciences into a coherent and all-comprehensive "corpus", is a sine qua non condition for human progress to be pursued further, and for modern civilisation to survive. In fact, that "We have inherited from our forefathers the keen longing for unified, all-embracing knowledge" ${ }^{\prime \prime}$, seemed to us unquestionable, even if difficult to justify by appealing to concise and compellingly cogent arguments. Anyway, it is with this grand scenario: present history, in the background; that today's individuals' plight to become an actual contemporary of his epoch, is at stake. We believed, and wrote, that the individual's attitude, tending either to earnestly and honestly face this exigency, or to avert it; is relevant regarding mental health and guessed it's due to come up in the psychiatrist's office, even if under manifold disguises, and out-and-out degradations: such as fanaticism...

... But, who knows which is the case in every circumstance? The dire dramatic truth about the greatest catastrophes menacing human civilization is, as last century's history teaches, that they are not only the result of wicked actions committed by a few wicked people; but moreover the outcome of the lack of a clear culturally meaningful aspiration toward contemporariness; and of the ensuing blind behaviour and mystified anachronism of myriads of good-willing people. And to be sure, it's nobody's privilege to tell the difference beforehand, without painstaking scientific endeavour which essentially consists in universal, stepwise, dialogue: so this is where the trans-disciplinary project we advocated, came in.

Since the publication we gained further insight; into what seems more and more to us a large, fertile, mostly unexplored territory; where subject matters customarily ascribed to disciplines instituted as poles apart (ours among them), overlap. Right now we're dealing with a rather small part of such vast terrain; and there are obvious ways, indeed; other than the one herein discussed; in which professional collaboration is due -and indeed ongoing; between these disciplines, well instanced in large scale health services planning, and more generally in mental health and related policies. We may also point in this connection to a narrowly syncretic and pragmaticallyminded interdisciplinary speciality, persistently elbowing a niche for itself into the official curriculum. Our focus however is rather different from these in several ways. We're not pointing so much at an "inter-disciplinary" approach, but rather to a trans-disciplinary strategy. Not excluding professional cooperation, our main bid is research.

With this in mind, we're eager to learn from the psychiatrist's experience about how our chronologic contemporaries fare in their daily plights and hardships -and yet manage a degree of enjoyment and hope. And we're mainly interested in the psychiatrist's theoretical endeavours; which, as far as they are effectively brought up into the concept, are bound to impinge upon economic thought and even enrichen basic economic theory. The latter has been conceived indeed upon extremely simplistic psychological assumptions; which was commendable and necessary and still is; as allows an initial analytic approach to distil purely economic behaviours from the cultural complexity of modern social scenarios. Important 
mechanistic -and eventually organicist; laws were thus obtained from mostly speculative constructions; the former very much in the guise of Newtonian physics; as summed up paradigmatically in the walrasian system of equations, enormously influential in $\mathrm{xx}$ century economic thought. (For a one-sided but ineludibly introductory account of this doctrine -that plays down such influential contributions as those from Adam Smith, David Ricardo, Karl Marx; see reference below: Patinkin, Don 1965). The idea behind such system of equations (that can be traced back to the disciples of Ockham in the late Middle Ages, and to mercantilists as Montanari in the xvii century, and especially to Hume's obiter dictum against protectionism in his Economic Writings) rendered a quite satisfactory explanation -or so it seemed; of how otherwise unconnected economic agents interacted in the modern economic world, in such a way that the latter behaved as a self-balanced system. This wonderful intellectual feat was already for the most part accomplished by the turn of the last century; i.e. decades before psychiatry itself -a late-comer to modern science, found a grip and held to it heroically, struggling to set itself free from anachronistic doctrines, and already saddling over the gapping schism that alienates natural and social sciences from each other.

In sum, however necessary they are as an analytical step towards conceptual development, such mainly nineteen century theories show themselves still too abstract to account for the recent and present structures of xxi century capitalism. So when we go back to those individual behaviour assumptions upon which those theories were premised, we find them wanting.

A further reason for our interest in this project is because we believe that as the psychiatrist delves into some unique circumstances facing singular individuals, he finds a main source of intellectual stimulus therein -and hopefully, theoretical inspiration: right in situ, by exerting their profession as a medical speciality. On one side, from our view, their privilege as researchers is having their subject matter within the range of their perception, their feelings, their emotions; and being able to actually interact with their subject matter as a living patient; in such a way that they'll both enter into an intense, intelligent, fruitful, vis-à-vis experience. We instead, due to the world-wide nature of our own subject matter, are deprived of such an advantage: we can only "see" such universal objects by means of theory; and then it has to be good theory (and we have to be able to tell the difference). But we have reasons to say that as long as those advantages we lack remain unilateral, they may not accrue as advantages at all. Pending further discussion, these reasons will (hopefully) transpire from the following paragraphs.

"Looking" (again, through concepts, from the economist's theoretic viewpoint) at the big fragmented picture of science and philosophy today: and "listening" (from the same angle) to present history's claim for a strategy towards a new synthesis, psychiatry draws our attention because of its success in bringing together psychology and biochemistry, and natural and social sciences thereby, into its own field. (And so do other medical fields, but also non-medical lines of research in social behaviour such as Praxeology, Ethology, Paleo-anthropology...).

As both the article we are reviewing and the review itself are mainly addressed to psychiatrists, we'd hope we could suggest to them how relevant (properly expounded) economic theory may be for their focus on research and therapy. On this regard we'll briefly venture a hypothesis; admittedly seasoned with pieces of speculation; not straightforwardly about what goes on within that that remains for us the sealed black box in the mind and feelings of any particular therapist's patient; but about his, their, historical entourage.

For this purpose, we call in a ghostly average individual: an imperfect but revealing holograph of his, facing the same or about the same overall socio-historical circumstances he may have confronted. Its individual singularity (as distinct from any other's) is cast off and annulled by abstraction within the average self in the holograph depicted. But, while the living individual -who's perhaps utterly unable to expound the concept of Self, and yet knows for certain if anything at all that he is an individual (and may be required to prove in his internet account that he's not a robot) ... may have gotten himself stuck into a murky obstacle blocking his way to self-realisation against which it struggles to no avail; the imaginary individual (represented in the holograph or otherwise) is posited in a limpidly clear and simplified world-setting where we wouldn't exaggerate too much by saying that his way on towards contemporariness is daylight clear in front of him.

The quid of this is of course that the holograph's scenario is itself a holograph, where we can easily "see" in full perspective and probable prospective; the types of stoppages and menaces interposed between the living individual and his progress towards becoming the fullfledged historical contemporary his own. Pending further discussion, a glance at the holograph may help us in tracing otherwise unexplainable (or not properly comprehensible) hindrances blocking our way to realisation. And what it shows is the holograph facing the triple culture aporia; which is the stumbling block we're trying to characterise, and the source of the plights every chronologic contemporary, and our epoch, has to acknowledge, and overcome. Which what it blows down to is, that we were bred into a first culture we call Family, where our basic world of emotions, sentiments of truth, reality, fairness, love, were first kindled. That soon after we found ourselves trying to make sense of, and make ends meet in, a second 
culture we'll call Metaphysic Capitalism, overriding the first; where the relevant objects of experience are not only or not at all perceptual but transcendental -even if no more in a religious sense; and only become intelligible by means of ideal archetypes or scientific theories; and, while the large majority struggles helplessly to conciliate the first two cultures and live a meaningful life; a new brutal circumstance wreaks havoc upon human civilisation, once and again. A few words are enough to say what it is about: the key word is History. Upon reflection anyone can understand that since the inception of human societies history has been going on as a heteronomous process ${ }^{6}$. Present history has reached the threshold where such heteronomy has become incompatible with modern civilisation and with the pursuance of human progress -if not with the survival of our species ${ }^{1}$. Human liberties will be entirely out of question if humans remain playthings of alien powers. The second culture does have provisions -mainly conceptual; for us to face this obstacle by means of universal, democratic, concerted action. Can our joint endeavour contribute to the making of the universal culture of mankind?

\section{References}

1. Cazenave A, Romero V, Levín P. El concepto de planificación tal como resulta del desarrollo teórico más avanzado de la economía política. Revista de Investigación en Economía y Responsabilidad Social. (2018). Volumen 1: No1.

2. Levín P, Cazenave A, Piqué P. Ensayo sobre el posible aporte de la economía política a la filosofía de la aspiración (en revisión). (2018).

3. Levín P. Esquema de la Ciencia Económica. Revista de Economía Política de Buenos Aires. (2010). Vol. 7/8, pp. 247-289.

4. Levín P. Concepto económico de salud mental: indagación exploratoria. Vertex. Revista Argentina de Psiquiatría. (2016). Volumen XXVII, Número 125 , pp. 25-34.

5. Schrödinger E. ¿Qué es la vida? Madrid, España: Ediciones Hyspamérica. ([1944] 1983).

6. Patinkin D. Money, interest and prices: An integration of monetary theory and value theory. NY, USA: Harper \& Row. (1956). 